\title{
Study Engagement and Burnout of the PhD Candidates in Medicine: A Person-Centered Approach
}

\author{
Lotta Tikkanen ${ }^{1,2 *}$, Kirsi Pyhältö̈ ${ }^{1,3}$, Aleksandra Bujacz ${ }^{4}$ and Juha Nieminen ${ }^{5}$ \\ ${ }^{1}$ Centre for University Teaching and Learning, Faculty of Educational Sciences, University of Helsinki, Helsinki, Finland, \\ ${ }^{2}$ School of Applied Educational Science and Teacher Education, Philosophical Faculty, University of Eastern Finland, \\ Joensuu, Finland, ${ }^{3}$ Faculty of Education, University of Oulu, Oulu, Finland, ${ }^{4}$ Behavioral Informatics Team, Health Informatics \\ Centre, Department of Learning, Informatics, Management, and Ethics, Karolinska Institutet, Stockholm, Sweden, \\ ${ }^{5}$ Department of Learning, Informatics, Management, and Ethics, Karolinska Institutet, Stockholm, Sweden
}

OPEN ACCESS

Edited by:

Sónia P. Gonçalves, University of Lisbon, Portugal

Reviewed by: Francesco Chirico,

Catholic University of the

Sacred Heart, Italy

Liliana Pitacho,

Instituto Superior Manuel Teixeira

Gomes, Portugal

Sara Paralta,

University of Lisbon, Portugal

*Correspondence:

Lotta Tikkanen

lotta.tikkanen@helsinki.fi

Specialty section:

This article was submitted to

Positive Psychology,

a section of the journal

Frontiers in Psychology

Received: 19 June 2021 Accepted: 28 October 2021 Published: 23 November 2021

Citation:

Tikkanen L, Pyhältö K, Bujacz A and Nieminen J (2021) Study

Engagement and Burnout of the PhD

Candidates in Medicine: A Person-

Centered Approach.

Front. Psychol. 12:727746.

doi: 10.3389/fpsyg.2021.727746
This study focused on exploring individual variations in doctoral candidates' well-being, in terms of experienced research engagement and burnout by using a person-centered approach. In addition, the associations between well-being profiles and gender, country of origin, study status (full-time or part-time), research group status and drop-out intentions were explored. The participants were $692 \mathrm{PhD}$ candidates in the field of medicine. Latent profile analysis was employed to identify the well-being profiles. Four distinct profiles were identified: high engagement-low burnout, high engagement-moderate burnout, moderate engagement-moderate burnout, and moderate engagement-high burnout. Working in a clinical unit or hospital and working in a research group seemed to be related to increased engagement and reduced risk for suffering burnout, while the intentions to quit one's doctoral studies were more frequently reported in profiles with moderate levels of engagement. The findings imply that although a significant number of $\mathrm{PhD}$ candidates in medicine had an increased risk for developing burnout, for most of the $\mathrm{PhD}$ candidates research education is an engaging experience.

Keywords: burnout, drop-out, PhD candidate, research engagement, well-being

\section{INTRODUCTION}

Undertaking a doctoral degree provides both highs and lows, potentially significantly reducing or increasing PhD candidates' well-being (e.g., Stubb et al., 2011; Divaris et al., 2012; Caesens et al., 2014; Hunter and Devine, 2016; Swords and Ellis, 2017). Yet, previous research on the topic has focused heavily on the negative attributes such as stress (e.g., Oswalt and Riddock, 2007; Pappa et al., 2020), depression (e.g. Peluso et al., 2011; Levecque et al., 2017), anxiety (e.g., Barry et al., 2018; Liu et al., 2019), and exhaustion (e.g., Hunter and Devine, 2016), while positive aspects of $\mathrm{PhD}$ experience have been studied to a lesser extent (Barnes and Randall, 2012; Sverdlik et al., 2018; Pyhältö et al., 2019). In particular, the number of studies exploring the combination or co-existence of positive and negative attributes of $\mathrm{PhD}$ candidates' well-being is limited (for an exception, see Stubb et al., 2011), although PhD candidate's wellbeing cannot be reduced simply to an absence of negative experiences (Schmidt and Hansson, 2018). 
A large body of research has indicated that the risk of burnout among physicians and other health care workers is high (van Vendeloo et al., 2018; Dyrbye et al., 2020; Woo et al., 2020). The COVID-19-pandemic has further increased the risk of burnout among health care workers (Chirico et al., 2021; Magnavita et al., 2021). In contrast, we know little about the well-being of research-active employees in the medical fields. Based on the literature on doctoral education, $\mathrm{PhD}$ candidates working in the medical context have rarely been studied. The medical research context is affected by the culture and hierarchy of the wider organizational culture of health care and hospital hierarchy, likely affecting PhD candidates' well-being (Kusurkar et al., 2021). Furthermore, there are at least two distinct subgroups of $\mathrm{PhD}$ students in these contexts (Naylor et al., 2016): those who also work clinically and those working in the basic sciences. These two groups of $\mathrm{PhD}$ candidates often work under very different conditions, within the same medical university setting (Naylor et al., 2016). More context-specific studies into PhD candidates in medical research education and the differing subgroups of $\mathrm{PhD}$ candidates in medicine have been called for (Naylor et al., 2016; Kusurkar et al., 2021).

In this study, we aimed to explore the individual variation in well-being among $\mathrm{PhD}$ candidates in medicine by employing a person-centered approach. We focused on identifying burnoutengagement profiles employed by $\mathrm{PhD}$ candidates in the medical fields, and how they are related to working in a clinical unit or hospital, study status (full-time or part-time), research group status, and drop-out intentions. Also, differences between international and native (Swedish) PhDs candidates, and men and women were examined.

\section{PhD Candidates' Well-Being}

$\mathrm{PhD}$ candidates' study well-being is a multidimensional construct referring to a combination of positive mental states, such as satisfaction, self-efficacy or/and study engagement, and absence of extensive and severe negative ones such as burnout or strain related to doctoral studies, further contributing to a candidates ability to pursue their study goals (Korhonen et al., 2014; Widlund et al., 2018). Study well-being is constructed in an interplay between demands and resources of the $\mathrm{PhD}$. candidate and their doctoral study environment (see on study well-being among undergraduates Salmela-Aro and Upadyaya, 2014). In this study, we explore $\mathrm{PhD}$. candidates' study well-being in terms of study engagement and burnout. It has been suggested that study engagement is a symbol of an optimal $\mathrm{PhD}$ experience, characterized by vigor, dedication, and absorption (Schaufeli et al., 2002b; Salmela-Aro and Upadyaya, 2012). Among PhD candidates, engagement is typically manifested as high levels of energy and mental resilience while working with one's doctoral research, a strong willingness to invest effort in the doctorate, a sense of significance, enthusiasm, and inspiration, and being fully focused on one's work, whereby time passes quickly (Virtanen and Pyhältö, 2012; Vekkaila et al., 2013, 2014). Engagement in doctoral study has been shown to be positively related to study progress and negatively to drop-out intentions (Castelló et al., 2016).
Study burnout, in turn, refers to a negative study experience that is characterized by two core symptoms, exhaustion and cynicism, resulting from prolonged stress (Schaufeli et al., 2002a; Salmela-Aro et al., 2009). Exhaustion refers to lack of emotional energy and chronic fatigue (Maslach and Jackson, 1981), and cynicism refers to alienation from one's studying, perceiving them as meaningless and losing interest in them (Maslach, 2003). Burnout during doctoral study has been shown to be related to delaying doctoral study and intending to quit them (Pyhältö et al., 2012; Anttila et al., 2015; Hunter and Devine, 2016; Cornér et al., 2017; Barry et al., 2018).

In variable-based studies, study engagement and burnout have typically been found to be negatively related to each other (Schaufeli et al., 2002a; González-Romá et al., 2006; Salmela-Aro and Upadyaya, 2012; Swords and Ellis, 2017). This means that the $\mathrm{PhD}$ candidates experiencing high levels of study engagement are likely to experience low levels of study burnout and vice versa. However, various combinations of study engagement and burnout are also possible (Tuominen-Soini and Salmela-Aro, 2014; Salmela-Aro and Read, 2017). For example, a $\mathrm{PhD}$ candidate can be highly engaged in their doctorate, but simultaneously experience high levels of exhaustion. A reason for this might the gradual development of burnout: burnout typically begins with exhaustion, and then, if working conditions remain the same, also the levels of cynicism increase (Maslach and Leiter, 2016). Studies using a person-centered approach to explore $\mathrm{PhD}$ candidates' study engagement and burnout simultaneously are scarce, resulting in a lack of knowledge about individual variations in the study well-being of $\mathrm{PhD}$ candidates in medicine. In addition, it is not known how different study well-being profiles are related to individual and contextual factors.

\section{Antecedents of PhD Students' Study Well-Being}

Research has identified several individual and contextual antecedents of $\mathrm{PhD}$ candidates' well-being. For instance, gender has been shown to be associated with study well-being, yet the evidence is mixed: although there is some evidence showing that female $\mathrm{PhD}$ students experience more stress and exhaustion than males (Toews et al., 1997; McAlpine et al., 2020), there is also evidence of male postgraduates being more likely to experience increased levels of exhaustion than their female colleagues. Hunter and Devine (2016), on the other hand, showed that $\mathrm{PhD}$ students' gender was not associated with their experiences of exhaustion. The mixed findings imply that gendered impact may be dependent on the socio-cultural or disciplinary practices.

Some differences between international and native $\mathrm{PhD}$ candidates have also been reported. It has also been suggested that international $\mathrm{PhD}$ candidates are more career-oriented and more satisfied with their doctoral studies, which might make them more likely to experience research engagement compared to native $\mathrm{PhD}$ candidates (Harman, 2003; Sakurai et al., 2017). However, international $\mathrm{PhD}$ candidates have also been shown to experience stress due to a lack of a supportive network 
(Pappa et al., 2020), which increases their risk of burnout. Yet, evidence concerning the differences between domestic and international $\mathrm{PhD}$ candidates' well-being is particularly limited.

Working conditions can be expected to have an impact on the well-being of $\mathrm{PhD}$ candidates in the medical fields. First, it has been suggested that the $\mathrm{PhD}$ candidates who are involved in clinical work experience high work strain due to constant balancing with their clinical or patient responsibilities and $\mathrm{PhD}$ research (Kusurkar et al., 2021), which makes them prone to burnout experiences. On the other hand, there is also evidence that real work-life experiences such as clinical work can inspire candidates in their doctoral studies, and thus contribute to increased engagement (see Vekkaila et al., 2013). In a qualitative case study, comparing clinically active and basic science $\mathrm{PhD}$ candidates in the same context, Naylor and others (2016) showed that clinical doctoral candidates were initially less competent in basic research skills than candidates who had learned these skills at earlier stages of their basic science education. An adjustment from an established position at the clinic to being a junior researcher in the laboratory was challenging. On the other hand, financial stress characterized the experience of the science candidates more than that of the clinicians. Clinical $\mathrm{PhD}$ candidates also saw research education as being more clearly connected to career opportunities in the future than their basic science counterparts in the same setting did. Perceived employment opportunities have been associated with lower burnout levels in biomedical $\mathrm{PhD}$ candidates (Nagy et al., 2019). Differences in the working conditions of medical $\mathrm{PhD}$ candidates may thus affect the levels of burnout and engagement in differing ways.

Research group status, i.e., whether the $\mathrm{PhD}$ candidate is undertaking their doctoral research within a research group or alone, can be assumed to have impact on study well-being. Research group has been shown to be an important source of social support to $\mathrm{PhD}$ candidates, and hence, working in a research group can be assumed to increase the experienced engagement (Stubb et al., 2011; Peltonen et al., 2017). However, it has also been found that working within a research group can be a source of stress (Stubb et al., 2011). Moreover, study status, i.e., whether the $\mathrm{PhD}$ candidate is undertaking their degree part-time vs. full-time, may have an impact on their study well-being. Yet, the evidence in this regard is partly contradictory. While those who work full-time are shown to be more satisfied with their supervision and perceive the scholarly community as empowering compared to those who work part-time (Stubb et al., 2011; Pyhältö et al., 2016), candidates working part-time are shown to be more satisfied with their mental health and friendships (Isohätälä et al., 2017).

\section{AIM OF THE STUDY}

The aim of the study was to understand the individual differences in study well-being among $\mathrm{PhD}$ candidates in medicine. More specifically, we explored the $\mathrm{PhD}$ candidates' study engagementburnout profiles and their associations with background variables that have previously shown to be associated with $\mathrm{PhD}$ candidates' well-being [i.e., gender, country of origin, and study status (i.e., whether they were completing their doctorate full-time or part-time], and research group status). We also explored whether PhD candidates classified into different study wellbeing profiles differed in their intensions to drop out from doctoral studies. The following general hypotheses were formulated:

H1: Different study engagement-burnout profiles can be detected among $\mathrm{PhD}$ candidates in medicine, ranging from profiles with high levels of burnout and low levels of engagement to profiles with low levels of burnout and high levels of engagement.

H2: The PhD candidates in the different study well-being profiles differ from each other in terms of gender, country of origin (i.e., domestic/international), and whether they are completing their doctorate full-time or part-time, and whether they work in hospital/clinical unit or not, and whether they worked with their doctorate alone or as a part of a research group (i.e., research group status).

H3: The PhD candidates with different study well-being profiles differ in their intentions to quit the doctoral studying, i.e., the students with high levels of burnout and low level of engagement are more likely to consider dropping out from the doctorate than those with low levels of burnout and high levels of engagement.

\section{MATERIALS AND METHODS}

\section{Research Context}

This study had a cross-sectional design. The data were collected during 2015-2016 through a web-based survey using a secure platform (Artologik). The survey was conducted in English. All $\mathrm{PhD}$ candidates at Karolinska Institutet with an activity rate of more than $10 \%^{1}$ received an invitation to participate in the survey. Karolinska Institutet is a research-oriented medical university with more than $2000 \mathrm{PhD}$ candidates enrolled. "Medical" is understood as an umbrella term encompassing a wide array of fields with a connection to medicine: From clinical research to a wide variety of basic research topics in microbiological and life sciences. Several allied health sciences, behavioral and medical social sciences, such as nursing, physiotherapy, occupational therapy, psychology, medical ethics, and management are also represented.

All participants were enrolled in the same university-wide research education program and have the same overall formal requirements for their training, regarding the number of credits required from research education courses, general criteria for quality of research work, and basic structures of supervision and quality control of the research education process. However, within that universal organizational framework there is great variation in terms of the topics investigated, practices of individual research groups and supervisors and departmental structures.

${ }^{1}$ Time devoted to a thesis is more than $4 \mathrm{~h} /$ week. 
There are clinical and basic science $\mathrm{PhD}$ candidates at Karolinska Institutet. The clinical $\mathrm{PhD}$ candidates typically work within two organizations: The hospital clinic or another health care organization (the manager or supervisor of the clinical work being the person the clinician reports to) and another one in the research group on the university side (the main doctoral supervisor most often being the candidate's responsible manager). The basic science $\mathrm{PhD}$ candidates only work within one organization, the university, and have their main supervisor in doctoral education.

In Sweden, all $\mathrm{PhD}$ candidates are fully financed, meaning that they get a monthly salary. Their salary level depends on a variety of factors, mainly the source of finance (for example, grants from abroad, external competitive research funding, research funding from medical industry, or funding provided by the healthcare system for their employees). Clinical $\mathrm{PhD}$ candidates typically have considerably higher salaries than their basic science counterparts.

The context of the current study is similar to many other natural science contexts in that much of the research work is done within a research group, and a collaborative "teamwork research training structure" (Chiang, 2003) is prevalent. However, there is considerable variation in this regard. At least two co-supervisors in addition to a main supervisor is an organizational norm.

\section{Participants}

In total, $2044 \mathrm{PhD}$ candidates were invited and 692 responded to the survey (response rate $34 \%$ ). $\mathrm{PhD}$ candidates were all in the medical fields. Of the participants, $61.3 \%$ were females and $36.6 \%$ males. The age of the participants ranged from 24 to 88 , the mean being 35 years. Forty six percent of the participants $(n=320)$ were Swedish and 53\% $(n=366)$ were from another country. Of the participants, $67.2 \% \quad(n=465)$ reported that they were completing their doctorate full-time and $32.7 \%$ part-time. Nearly one-third $(32.7 \%, n=226)$ of the participants were working in a hospital or a clinical unit. The proportion of those working mainly on their own with their doctorate was $54.8 \% \quad(n=379)$, and $44.4 \% \quad(n=307)$ of the participants reported that they were working in a research team.

Participants were informed that participation was completely voluntary and that they may withdraw from the study at any time without providing any explanation. They were also informed that all of the data which they provided would be strictly anonymous and treated confidentially, responses to the survey would not be linked to any other personal data and that analyses would be made at the group level. Before completing the survey, participants indicated that they had read and understood the information provided above and whether they agreed to participate in the study. The research was approved by the Swedish Central Ethical Review Board (Ref. No\#2015/1626-31/5).

\section{Measures}

The participants completed the cross-country doctoral experience (C-DES) survey (see C-DES manual Pyhältö et al., 2018; Castelló et al., 2018). In this study, we used the following C-DES-scales to study PhD students' study well-being: (1) research engagement
(5 items) and (2) burnout in studying consisting of two factors: (a) exhaustion (4 items) and (b) cynicism (5 items). All items were rated on seven-point scales $(1=$ not at all, $2=$ very rarely, $3=$ rarely, $4=$ sometimes, $5=$ often, $6=$ very often, $7=$ all the time; See Appendix 1 for the items). Mean variables were formed to represent research engagement, exhaustion, and cynicism in studying. The Cronbach alpha reliability and descriptive statistics of the subscales are shown in Table $\mathbf{1}$.

\section{Data Analyses}

A latent profile analysis (LPA) was used to identify subgroups of individuals based on their experiences of study engagement and burnout. LPA is a person-centered approach that involves grouping individuals into latent classes based on their observed response patterns on specific variables instead of exploring the relationships between the variables (Berlin et al., 2014). LPA provides statistical criteria for model comparisons in selecting the best-fitting number of latent classes and opportunity to include predictors and outcomes compared to other clustering approaches (e.g., Vermunt and Magidson, 2002; Morin et al., 2018). The analyses were carried out using Mplus version 8.6 and MLR estimator that produces maximum likelihood estimates with standard errors and $\chi^{2}$ test statistics that are robust to non-normality (Muthén and Muthén, 1998-2017). Within-class variances were held constant across classes. We used several statistical criteria to choose the best fitting model: The Akaike (AIC), the Bayesian (BIC), adjusted Bayesian (aBIC) information-based measures of fit, and a VuongLo-Mendell-Rubin (VLMR) and Lo-Mendell-Rubin (aLRT), and bootstrapped (BLRT) likelihood ratio tests (Nylund et al., 2007; Berlin et al., 2014). In addition, the theoretical meaningfulness of the profile solution was emphasized in selecting the number of profiles. The average latent class probabilities and entropy values were used to evaluate the clarity of different profile solutions.

To explore whether the $\mathrm{PhD}$ candidates with different study well-being profiles differed from each other in terms of background variables (gender, country of origin, working in clinical unit or hospital, study status (full-time or part-time), research group status), we used auxiliary Mplus command (Muthén and Muthén, 1998-2017). The background variables were included as antecedents of the latent class variable while accounting for the measurement error in classification (Asparouhov and Muthén, 2014). This analysis was carried out with the R3STEP procedure of Mplus that performs a multinomial logistic regression and provides the odds ratios describing the effect of background variables on the likelihood of membership in each of the latent profiles compared to other profiles (McLarnon and O'Neill, 2018). DCAT procedure for Mplus was used for examining whether candidates in different profiles differed from each other in terms of their intentions to quit studying for their doctorate.

\section{RESULTS}

\section{The Study Well-Being Profiles}

LPAs were run with 1-6 classes (Table 2). According to VLMR and aLRT likelihood ratio tests, adding a subsequent class 
TABLE 1 | Descriptive statistics and correlations of the study variables.

\begin{tabular}{|c|c|c|c|c|c|c|c|c|}
\hline & $N$ & $\alpha$ & $M$ & $S D$ & Min/Max & 1 & 2 & 3 \\
\hline 1. Exhaustion & 692 & 0.837 & 3.65 & 1.19 & $1 / 7$ & - & & \\
\hline 2. Cynicism & 692 & 0.895 & 3.00 & 1.35 & $1 / 7$ & $0.56 * *$ & - & \\
\hline 3. Engagement & 690 & 0.918 & 4.90 & 1.00 & $1 / 7$ & $-0.22 * *$ & $-0.60 * *$ & - \\
\hline
\end{tabular}

$* * p<0.001$.

TABLE 2 | Information criteria values for different profile solutions in LPAs.

\begin{tabular}{|c|c|c|c|c|c|c|c|c|c|c|}
\hline No. classes & $\operatorname{LogL}(n f)$ & AIC & BIC & $\mathrm{aBIC}$ & Entropy & $\begin{array}{l}\text { Latent class } \\
\text { probabilities }\end{array}$ & VLMR & aLRT & BLRT & $\begin{array}{l}\text { Class } \\
\text { counts }^{a}\end{array}$ \\
\hline 1 & $-3268.89(6)$ & 6549.77 & 6577.01 & 6557.96 & N/A & 1.00 & $\mathrm{~N} / \mathrm{A}$ & N/A & N/A & \\
\hline 2 & $-3073.97(10)$ & 6167.93 & 6213.33 & 6181.58 & 0.72 & $0.93,0.89$ & 0.00 & 0.00 & 0.00 & $\begin{array}{c}431,261 \\
(430,262)\end{array}$ \\
\hline 3 & $-2983.58(14)$ & 5995.16 & 6058.71 & 6014.26 & 0.80 & $\begin{array}{c}\text { 0.93, } 0.89 \\
0.90\end{array}$ & 0.00 & 0.00 & 0.00 & $\begin{array}{c}286,319,87 \\
(282,325 \\
85)\end{array}$ \\
\hline 4 & $-2953.34(18)$ & 5942.67 & 6024.39 & 5967.23 & 0.80 & $\begin{array}{c}0.93,0.93 \\
0.86,0.87\end{array}$ & 0.01 & 0.02 & 0.00 & $\begin{array}{c}226,62,230, \\
174(227,60, \\
231,174)\end{array}$ \\
\hline 5 & $-2927.05(22)$ & 5898.10 & 5997.97 & 5928.12 & 0.84 & $\begin{array}{c}0.94,0.94 \\
0.90,0.86 \\
0.88\end{array}$ & 0.02 & 0.02 & 0.00 & $\begin{array}{c}222,7,68 \\
222,173 \\
(223,7,69 \\
224,169)\end{array}$ \\
\hline 6 & $-2914.54(26)$ & 5881.09 & 5999.12 & 5916.56 & 0.85 & $\begin{array}{c}0.92,0.87 \\
0.97,0.93 \\
0.86,0.90\end{array}$ & 0.02 & 0.02 & 0.00 & $\begin{array}{c}9,170,7, \\
221,222,62 \\
(7,169,7 \\
223,223,63)\end{array}$ \\
\hline
\end{tabular}

LogL, log likelihood value; nf, number of free parameters; AIC, Akaike information criterion; BIC, Bayesian information criterion; aBIC, adjusted Bayesian information criterion; VLMR, VuongLo-Mendell-Rubin likelihood ratio test; aLRT, Lo-Mendell-Rubin adjusted likelihood ratio test; BLRT, bootstrapped likelihood ratio test. The selected model is in boldface. ${ }^{a}$ Profile counts based on estimated posterior probabilities and the classification of individuals based on their most likely latent profile membership (in parenthesis).

increased the model fit all the way to six classes, while the information criteria (AIC, BIC, and aBIC) showed that adding a new latent profile enhanced the model fit all the way to five profiles. However, the elbow plot (Figure 1) showed that the BIC and aBIC values clearly decreased from one to four profiles, after which the decline levelled off. Therefore, the four-profile solution was selected. The four-profile solution was also considered to be the most parsimonious model, had a clear theoretical interpretation, and included profiles with sufficiently large memberships (i.e., $>5 \%$ of the cases). The entropy value $(0.80)$ and latent class probabilities $(>0.80)$ also showed sufficient separation between the profiles in the fourprofile solution showed sufficient separation between the profiles.

Four well-being profiles were identified (Figure 2). The first study well-being profile was high engagement-low burnout profile (see Table 3). It was the second most common profile among the participants with a 32.7 percent share $(n=226)$. The $\mathrm{PhD}$ candidates in this profile reported rather high levels of study engagement meaning that they often felt enthusiastic and inspired by their doctoral work. They reported low levels of cynicism, but moderate levels of exhaustion. However, when compared to other profiles, the exhaustion levels were lowest in this profile.

The second profile was high engagement-moderate burnout profile, and it was the most common profile among the participants with a 33.2 percent share $(n=230)$. The $\mathrm{PhD}$ candidates within this profile reported moderate levels of both exhaustion and cynicism, and high levels of study engagement. The third profile was moderate engagement-moderate burnout profile. It represented 25.1 percent of the participants $(n=174)$. The $\mathrm{PhD}$ candidates with this profile demonstrated moderate levels of study engagement, exhaustion, and cynicism. This means that although the $\mathrm{PhD}$ candidates within this profile felt rather inspired and enthusiastic about their doctoral studies, they also sometimes felt overwhelmed by the doctoral study related workload and perceived their doctoral studies as meaningless. The fourth profile was moderate engagement-high burnout profile. The $\mathrm{PhD}$ candidates with this profile reported high levels of both exhaustion and cynicism. The candidates' high levels of study burnout were combined with moderate levels of study engagement. This profile represented 9.0 percent of the participants $(n=62)$ being the least common profile.

The profiles differed statistically significantly $(p<0.01)$ from each other in all study variables, research engagement, exhaustion, and cynicism.

\section{The Antecedents of Study Well-Being Profiles}

Gender and country of origin did not have statistically significant relationships with study well-being profiles. 


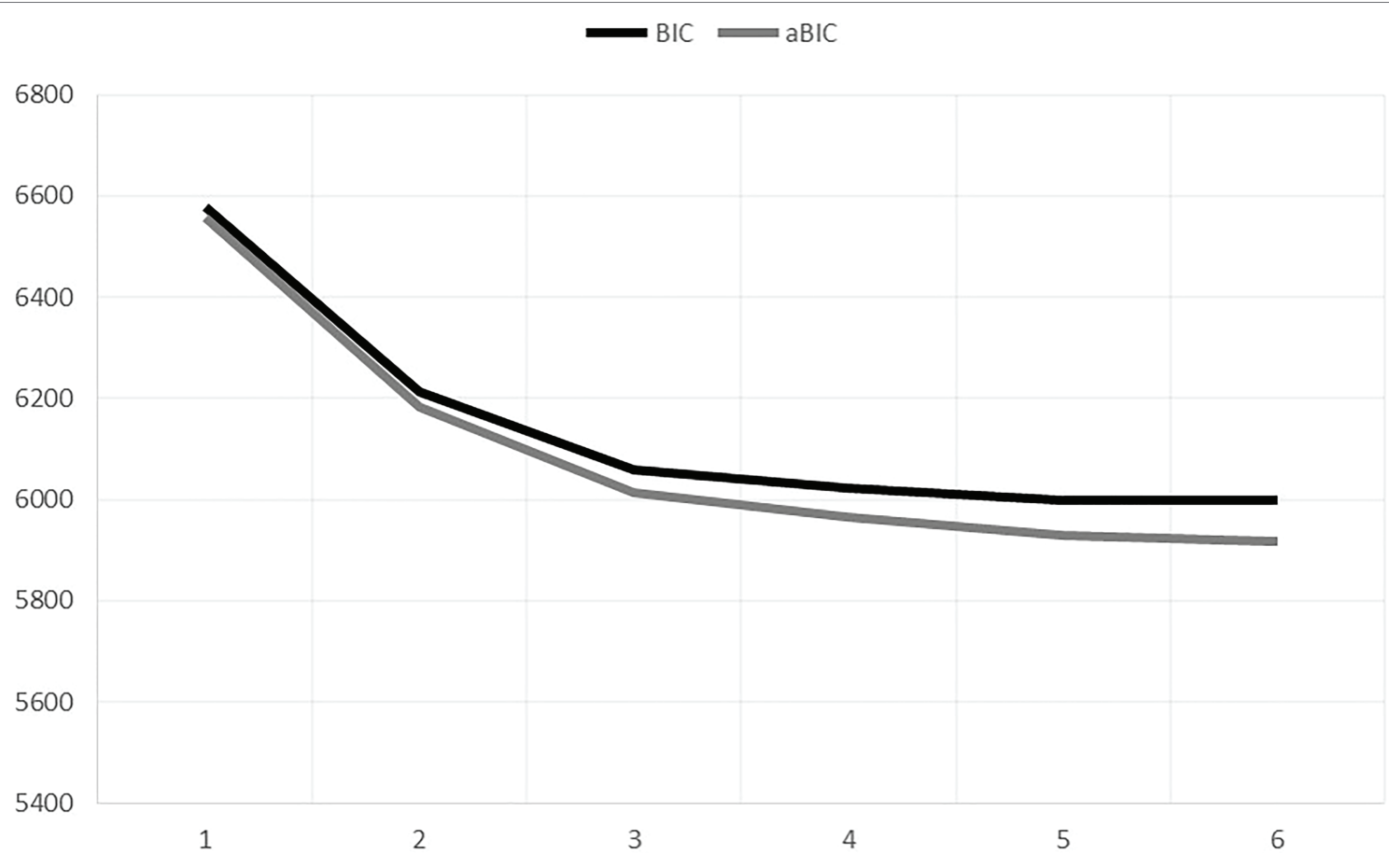

FIGURE 1 | Elbow plot of information criteria for different profile solutions.

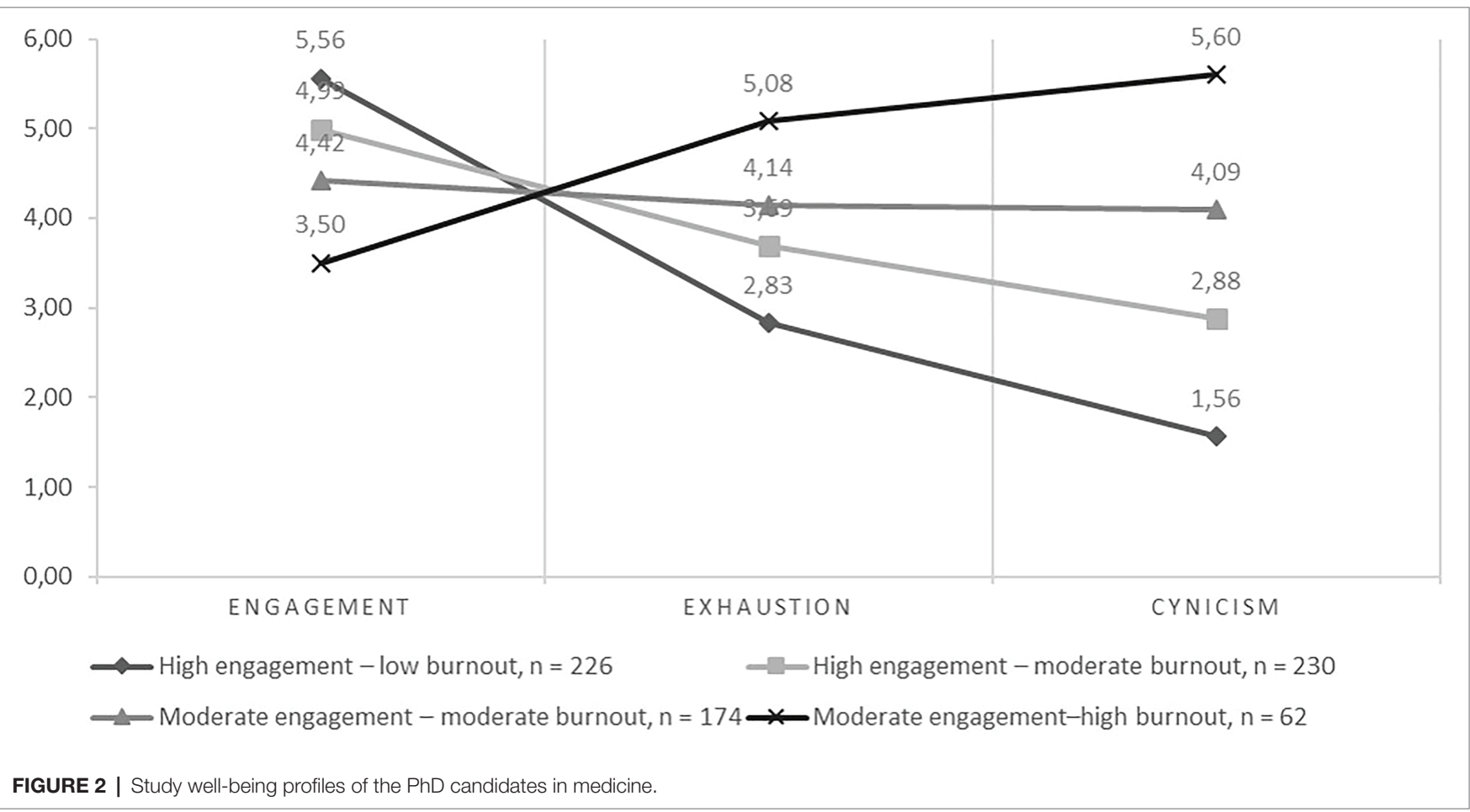

Whether the PhD candidates were completing their doctorate full-time or part-time did not predict the profile membership either.

The $\mathrm{PhD}$ candidates who reported that they were working alone with their doctoral thesis had higher odds of belonging to moderate engagement-high burnout profile than to high engagement-moderate burnout profile $(b=0.98, \mathrm{SE}=0.38$, $p=0.011, \mathrm{OR}=2.86,95 \% \mathrm{CI}[1.25-5.64])$ or high engagement-low burnout profile $(b=1.35, \quad \mathrm{SE}=0.38, \quad p<0.001, \quad \mathrm{OR}=4.22$, 95\% CI[1.83-8.11]) compared to those who were completing 
TABLE 3 | Profile means and standard deviations.

\begin{tabular}{|c|c|c|c|c|c|c|c|c|}
\hline & \multicolumn{2}{|c|}{$\begin{array}{l}\text { High engagement- low } \\
\text { burnout }\end{array}$} & \multicolumn{2}{|c|}{$\begin{array}{l}\text { High engagement- moderate } \\
\text { burnout }\end{array}$} & \multicolumn{2}{|c|}{$\begin{array}{l}\text { Moderate engagement - } \\
\text { moderate burnout }\end{array}$} & \multicolumn{2}{|c|}{$\begin{array}{l}\text { Moderate engagement-high } \\
\text { burnout }\end{array}$} \\
\hline & $\mathbf{M}$ & SD & $\mathbf{M}$ & SD & $\mathbf{M}$ & SD & $\mathbf{M}$ & SD \\
\hline Engagement & 5.56 & 0.743 & 4.99 & 0.709 & 4.42 & 0.819 & 3.50 & 1.13 \\
\hline Exhaustion & 2.83 & 0.964 & 3.69 & 0.932 & 4.14 & 0.981 & 5.08 & 1.12 \\
\hline Cynicism & 1.56 & 0.437 & 2.88 & 0.467 & 4.09 & 0.483 & 5.60 & 0.578 \\
\hline
\end{tabular}

their doctorate in a research group. In addition, the $\mathrm{PhD}$ candidates who reported that they were working alone with their doctorate had higher odds of belonging to the moderate engagement-moderate burnout profile than to the high engagement-low burnout profile $(b=0.83, \mathrm{SE}=0.25, p=0.001$, $\mathrm{OR}=2.28,95 \% \mathrm{CI}[1.39-3.75])$ compared to those working in research groups.

The PhD candidates who were working in a clinical unit or hospital had higher odds of belonging to high engagementlow burnout profile than to moderate burnout-moderate engagement $(b=0.61, \quad \mathrm{SE}=0.29, \quad p=0.037, \quad \mathrm{OR}=1.85$, 95\% CI[1.04-3.25]) or moderate engagement-high burnout $(b=1.30, \quad \mathrm{SE}=0.52, \quad p=0.012, \quad \mathrm{OR}=3.56, \quad 95 \% \mathrm{CI}[1.30-9.72])$ profiles compared to those who reported that they were not working in a clinical unit or hospital. Those working in hospital or clinical unit also had higher odds of belonging to high engagement-moderate burnout $(b=1.23, \mathrm{SE}=0.50, p=0.015$, $\mathrm{OR}=3.66,95 \% \mathrm{CI}[1.33-10.10]$ ) profile than to moderate engagement-high burnout profile than those who were not working in a clinical unit or hospital.

Taken together, the $\mathrm{PhD}$ candidates who reported that they were working alone with their doctorate had higher odds of belonging to profiles displaying lower levels of engagement and higher levels of burnout compared to those working in a research group. In turn, the $\mathrm{PhD}$ candidates who reported working in a clinical unit or hospital had higher odds of belonging to profiles displaying higher levels of engagement and lower levels of burnout compared to those who were not at a clinical unit or hospital.

\section{Differences Between PhD Candidates in Different Profiles in Their Dropout Intentions}

The PhD candidates in various profiles differed statistically significantly from each other in terms of their dropout intentions $\left[\chi^{2}(3, N=690)=147.6, p<0.001\right]$. The intentions to interrupt one's doctoral studies were most frequently reported in the following profiles: moderate engagement-high burnout profile (74.7\%) of the $\mathrm{PhD}$ candidates with this profile had considered dropping out) and moderate engagement-moderate burnout profile (53.4\%). However, the candidates with profiles characterized by high study engagement reported less intentions to interrupt their doctoral studies: $7.2 \%$ of the $\mathrm{PhD}$ candidates with high engagement-low burnout profile and $16.6 \%$ with the high engagement-moderate burnout profile had considered dropping out.

\section{DISCUSSION}

\section{Findings in the Light of the Literature}

In this study, we explored $\mathrm{PhD}$ candidates' research engagementburnout profiles. Adopting a person-centered approach allowed us to explore individual variation in $\mathrm{PhD}$ candidates' study well-being by considering both positive and negative attributes of well-being at the same time rather than concentrating on the negative ones which has been the focus of several previous studies (e.g., Oswalt and Riddock, 2007; Peluso et al., 2011; Levecque et al., 2017; Pappa et al., 2020). Four distinct profiles among the $\mathrm{PhD}$ candidates in the field of medicine were identified: high engagement-low burnout, high engagement-moderate burnout, moderate engagement-moderate burnout, and moderate engagement-high burnout. The person-oriented approach complements variable-based studies showing a negative association between engagement and burnout (Schaufeli et al., 2002a; González-Romá et al., 2006; Salmela-Aro and Upadyaya, 2012; Swords and Ellis, 2017) by indicating that there are individual differences in how exhaustion, cynicism, and engagement can combine within a person. Our findings supported the bivariant approach on burnout and engagement, positing that burnout and engagement present two distinct, yet related dimensions of the individual's affective study related experiences (Shraga and Shirom, 2009; Larsen and McGraw, 2011; Shirom, 2011).

The results showed that the levels of research engagement were high or moderate in all the profiles and the most common profiles were those displaying high levels of engagement. Thus, the results indicate that undertaking doctoral studies in the field of medicine is a highly engaging experience. However, the results also showed that the risk of experiencing study burnout was also elevated (i.e., moderate or high) among most of the PhD candidates. These results are in line with earlier findings (Kusurkar et al., 2021) suggesting an increased risk of burnout in medical researcher education.

The results also showed that those $\mathrm{PhD}$ candidates who reported working alone with their doctoral studying were more likely to belong to the profiles displaying moderate levels of engagement and higher levels of burnout. This implies that engaging in researcher group provides a potential resource for cultivating not only study progress but also the candidate's well-being, identified also in previous studies (Pyhältö et al., 2009; Stubb et al., 2011; Peltonen et al., 2017). Interestingly, although medicine presents typical group-based discipline, i.e., the basic unit for conducting research is a research group providing the platform for researcher education, according to our results only about half of the candidates reported that they were engaged in a 
research group. This implies that formal research group structure does not automatically guarantee an experience of membership or a well-functioning collaboration with the research group.

The results showed that the $\mathrm{PhD}$ candidates who were working in a hospital or clinical unit had lower risk of experiencing burnout and were more likely to experience high levels of study engagement than others. This means that undertaking one's doctoral degree when having clinical responsibilities might protect the $\mathrm{PhD}$ candidates from study burnout and support their study engagement. On the contrary, Kusurkar et al. (2021) found that candidates in clinical departments had lower autonomy and higher levels of conflict between work responsibilities, especially among those $\mathrm{PhD}$ candidates who were working with patients. A variety of factors may explain our finding. The relevance of the research itself and doctoral studies in general might become apparent in the clinical work and hence, be a source of research engagement (see also Vekkaila et al., 2013). On the other hand, the candidates engaging in clinical work might have more extensive support networks to draw from as a resource for their studying and recovery when needed. They might be also less stressed by their career prospects after completing the $\mathrm{PhD}$ degree or they might be aiming for a non-academic career to reduce the stress caused by the doctoral studies (see Nagy et al., 2019). In addition, financial security may explain the differences in burnout levels: Clinical $\mathrm{PhD}$ candidates typically receive a much higher salary than $\mathrm{PhD}$ candidates who do not have clinical training or employment. In addition, basic science researchers will typically rely on external, competitive funding not only for the research work itself but even for maintaining a position at the university, thereby having much lower job security than their clinically active counterparts, who always have the chance of increasing the proportion of clinical work, should funding for research be scarce.

International $\mathrm{PhD}$ candidates did not differ in their likelihood of belonging to any subgroup. As previous studies have suggested that although international students might be prone to experience stress (Pappa et al., 2020), they are also likely to be motivated and satisfied with their studying (Harman, 2003; Sakurai et al., 2017), and thus be likely to experience research engagement. To our knowledge, no earlier study has looked at engagement and burnout of international doctoral students specifically in the medical research education, a context that tends to be extremely international and intercultural. Based on this finding, it seems that there were no distinctive differences between the international and native $\mathrm{PhD}$ candidates regard to their engagement-burnout-profiles. Accordingly, this suggests that the international $\mathrm{PhD}$ candidates in the field of medicine are highly heterogeneous group in terms of study well-being, not primarily determined by their status as international students. For example, it might be that whether they experienced working alone or within a research group or were clinical vs. basic science medical $\mathrm{PhD}$ candidates, were more significant in terms of their well-being than being an international $\mathrm{PhD}$ student.

The $\mathrm{PhD}$ candidates within the profiles displaying moderate levels of engagement and moderate or high levels of burnout symptoms more often reported intention to quit the doctoral degree than those with high levels of engagement, which was in line with previous findings (Anttila et al., 2015; Cornér et al., 2017). Hence, in addition to having mental health benefits, high levels of experienced engagement are related to study progress among $\mathrm{PhD}$ candidates in the field of medicine. Accordingly, investing in developing engaging doctoral education environments has potentially significant individual and organizational benefits, considering that according to previous studies, drop-out rates among the $\mathrm{PhD}$ candidates typically range from 25 to $60 \%$ (e.g., Council of Graduate Schools, 2004; Golde, 2005; McAlpine and Norton, 2006; Gardner, 2009).

\section{Limitations of the Study}

There are some methodological limitations in the study that need to be considered when interpreting the results. First, the criteria for selecting the number of profiles were ambiguous (Nylund et al., 2007), and hence, further studies exploring whether similar profiles can be found among other groups of $\mathrm{PhD}$ candidates are needed. For example, models for how profiles can be reproduced in new samples are being developed and may be helpful in exploring the well-being of $\mathrm{PhD}$ candidates across different medical research contexts (e.g., Gillet et al., 2021). Second, it is important to note that due to cross-sectional design, causal or process-related conclusions between study well-being and dropping out cannot be drawn. Third, the survey was sent to all doctoral students at the university simultaneously. Although the number of students who responded is sufficient for the analyses conducted, the sample only represents $36 \%$ of all doctoral students enrolled in the program. This should be kept in mind when generalizing, as we do not know whether self-selection might have affected the results. Fourth, the study was carried out in a specific social-cultural country context and in health sciences, accordingly one should be careful in drawing conclusions based on the results, across the doctoral education systems or disciplines. Last, it is important to note that data were collected before the COVID-19-pandemic. The pandemic has affected both the clinical and basic-science doctoral students in many ways. Further studies are needed to explore how stress, engagement and well-being of doctoral students working in the medical context have been affected by the pandemic at its different phases and afterwards.

\section{CONCLUSION}

Undertaking a $\mathrm{PhD}$ in medical fields is an engaging experience for most of the $\mathrm{PhD}$ candidates. However, the results suggested that there are several $\mathrm{PhD}$ candidates with high or increased risk of burnout. Thus, it seems that individual differences occur between $\mathrm{PhD}$ candidates in terms of their well-being. For individußals displaying a higher risk of burnout, it was more common to experience studying alone in their $\mathrm{PhD}$ compared to those with lower burnout risk. In addition, the lower risk of burnout was related to working in a clinical unit or hospital. Therefore, it can be concluded that in the field of medicine, working in research group, and in a clinical unit or hospital during their $\mathrm{PhD}$ can help buffering study burnout and provide sources of research engagement. 


\section{Practical Implications}

The results of the present study can be used by educational developers and staff trainers working with doctoral education. The stressors experienced by basic science $\mathrm{PhD}$ candidates in the highly competitive, externally funded research universities need to be taken into consideration by supervisors and policymakers. Particular attention should be paid to the candidates who experience that they are studying alone. Supervisors should be encouraged to be particularly careful in mapping out the actual support networks of their $\mathrm{PhD}$ candidates, instead of just formal connections to officially defined research groups. Moreover, the similarities and differences between the conditions of the clinical and non-clinical $\mathrm{PhD}$ candidates are worth discussing, as they work in the same general setting. The positive news for medical universities is that despite the pressures and competing responsibilities, the medical research setting is often experienced as engaging and does not automatically lead to burnout, a message worth spreading in this community engaged with cutting-edge, life-saving academic research. The study also has implications for policymakers: the findings highlight the importance of surveillance of the occupational health within the hospitals to check the psychosocial risk factors for staff undergoing research education, not merely that of residents and other health care workers.

The results also provide directions for future research on $\mathrm{PhD}$ candidates' well-being. Our findings suggested that although an official membership in a research group is common in medical university, over half of the participants in this study reported that they were working alone. Working alone instead of within a research group was more common in profiles with higher burnout levels and lower levels of engagement. Therefore, reasons for the finding that most of the participants experienced working alone needs to be studied further. For example, investigation is needed to see if working alone is an active choice of a candidate or whether it represents a failure of the research education system in ensuring a supportive setting for doctoral students. In such further investigations, special attention should be paid to the actual networks, communities of practice and support. Also, factors involved in medical doctoral students' engagement and burnout warrant closer investigation. As engagement may be more of a day-to-day experience, while burnout takes more time to develop (Sonnentag, 2017), it might

\section{REFERENCES}

Anttila, H., Lindblom-Ylänne, S., Lonka, K., and Pyhältö, K. (2015). The added value of a $\mathrm{PhD}$ in medicine - $\mathrm{PhD}$ students' perceptions of acquired competences. Int. J. High. Educ. 4, 172-180. doi: 10.5430/ijhe.v4n2p172

Asparouhov, T., and Muthén, B. (2014). Auxiliary variables in mixture modeling: three-step approaches using Mplus. Struct. Equ. Model. Multidiscip. J. 21, 329-341. doi: 10.1080/10705511.2014.915181

Barnes, B. J., and Randall, J. (2012). Doctoral student satisfaction: An examination of disciplinary, enrollment, and institutional differences. Res. High. Educ. 53, 47-75. doi: 10.1007/s11162-011-9225-4

Barry, K. M., Woods, M., Warnecke, E., Stirling, C., and Martin, A. (2018). Psychological health of doctoral candidates, study-related challenges and be useful to look more closely at the sources of engagement for both the clinically active and the basic science subgroups of medical $\mathrm{PhD}$ candidates, both to identify them more precisely and to investigate the variability and trajectory of them. Given the highly competitive, high-pressure nature of research-oriented medical contexts, it might also be useful to look at experiences of exhaustion as separate from fully developed burnout, as recent research indicates that weariness does not necessarily develop into more serious burnout (Gustavsson et al., 2010; Gillet et al., 2021). For PhD candidates, supervisors, and decisionmakers in these competitive environments, where high workload is more the norm than the exception, a more detailed understanding of these processes would be invaluable in terms of identifying high-risk situations and individuals in urgent need of help.

\section{DATA AVAILABILITY STATEMENT}

The raw data supporting the conclusions of this article will be made available by the authors, without undue reservation.

\section{ETHICS STATEMENT}

The research was approved by the Swedish Central Ethical Review Board (Ref. No\#2015/1626-31/5). The participants provided their written informed consent to participate in this study.

\section{AUTHOR CONTRIBUTIONS}

$\mathrm{LT}, \mathrm{KP}, \mathrm{AB}$, and JN have contributed to writing the original draft and editing it. $\mathrm{AB}$ has contributed to data collection and project administration. LT has contributed to conducting the analyses. All authors contributed to the article and approved the submitted version.

\section{SUPPLEMENTARY MATERIAL}

The Supplementary Material for this article can be found online at: https://www.frontiersin.org/articles/10.3389/fpsyg.2021.727746/ full\#supplementary-material. perceived performance. High. Educ. Res. Dev. 37, 468-483. doi: 10.1080/07294360.2018.1425979

Berlin, K. S., Williams, N. A., and Parra, G. R. (2014). An introduction to latent variable mixture modeling (part 1): overview and cross-sectional latent class and latent profile analyses. J. Pediatr. Psychol. 39, 174-187. doi: 10.1093/ jpepsy/jst084

Caesens, G., Stinglhamber, F., and Luypaert, G. (2014). The impact of work engagement and workaholism on well-being. The role of work-related social support. Career Dev. Int. 19, 813-835. doi: 10.1108/CDI-09-20130114

Castelló, M., McAlpine, L., and Pyhältö, K. (2016). Spanish and UK post-PhD researchers: writing perceptions, well-being and productivity. High. Educ. Res. Dev. 36, 1108-1122. doi: 10.1080/07294360.2017.1296412 
Castelló, M., Pyhältö, K., and McAlpine, L. (2018). "European cross-national mixed-method study on early career researcher experience," in The Postdoc Landscape: The Invisible Scholars. ed. A. J. Jaeger (Dinin London: Academic Press), 143-174.

Chiang, K. H. (2003). Learning experiences of doctoral students in UK universities. Int. J. Sociol. Soc. Policy 23, 4-32. doi: 10.1108/01443330310790444

Chirico, F., Ferrari, G., Nucera, G., Szarpak, L., Crescenzo, P., and Ilesanmi, O. (2021). Prevalence of anxiety, depression, burnout syndrome, and mental health disorders among healthcare workers during the COVID-19 pandemic: A rapid umbrella review of systematic reviews. J. Health Soc. Sci. 6, 209-220. doi: $10.19204 / 2021 / \operatorname{prvl} 7$

Cornér, S., Löfström, E., and Pyhältö, K. (2017). The relationships between doctoral students' perceptions of supervision and burnout. Int. J. Dr. Stud. 12, 91-106. doi: 10.28945/3754

Council of Graduate Schools. (2004). Ph.D. Completion and Attrition: Policy, Numbers, Leadership, and Next Steps. Washington, DC: Council of Graduate Schools.

Divaris, K., Polychronopoulou, A., Taoufik, K., Katsaros, C., and Eliades, T. (2012). Stress and burnout in postgraduate dental education. Eur. J. Dent. Educ. 16, 35-42. doi: 10.1111/j.1600-0579.2011.00715.x

Dyrbye, L. N., West, C. P., Halasy, M., O'Laughlin, D. J., Satele, D., and Shanafelt, T. (2020). Burnout and satisfaction with work-life integration among PAs relative to other workers. JAAPA 33, 35-44. doi: 10.1097/01. JAA.0000660156.17502.e6

Gardner, S. K. (2009). Conceptualizing success in doctoral education: perspectives of Faculty in Seven Disciplines. Rev. High. Ed. 32, 383-406. doi: 10.1353/ rhe. 0.0075

Gillet, N., Morin, A. J. S., Colombat, P., Ndiaye, A., and Fouquereau, E. (2021). Burnout profiles: dimensionality, replicability, and associations with predictors and outcomes. Curr. Psychol. 4, 1-9. doi: 10.1007/s12144-021-01807-3

Golde, C. M. (2005). The role of the department and discipline in doctoral student attrition: lessons from four departments. J. Higher. Educ. 76, 669-700. doi: 10.1080/00221546.2005.11772304

González-Romá, V., Schaufeli, W. B., Bakker, A. B., and Lloret, S. (2006). Burnout and work engagement: independent factors or opposite poles? J. Vocat. Behav. 68, 165-174. doi: 10.1016/j.jvb.2005.01.003

Gustavsson, J. P., Hallsten, L., and Rudman, A. (2010). Early career burnout among nurses: Modelling a hypothesized process using an item response approach. Int. J. Nurs. Stud. 47, 864-875. doi: 10.1016/j. ijnurstu.2009.12.007

Harman, G. (2003). International PhD students in Australian universities: financial support, course experience and career plans. Int. J. Educ. Dev. 23, 339-351. doi: 10.1016/S0738-0593(02)00054-8

Hunter, K. H., and Devine, K. (2016). Doctoral students' emotional exhaustion and intentions to leave academia. Int. J. Dr. Stud. 11, 35-61. doi: $10.28945 / 3396$

Isohätälä, J., Louis, J.-N., Mikkonen, K., and Pyhältö, K. (2017). Towards a Doctoral Degree and Future Career - Perceptions of Doctoral Students at the University of Oulu. Acta universitatis Ouluensis F scripta academica 12. University of Oulu.

Korhonen, J., Linnanmäki, K., and Aunio, P. (2014). Learning difficulties, academic well-being and educational dropout: A person-centred approach. Learn. Individ. Differ. 31, 1-10. doi: 10.1016/j.lindif.2013.12.011

Kusurkar, R. A., van der Burgt, S. M. E., Isik, U., Mak-van der Vossen, M., Wilschut, J., Wouters, A., et al. (2021). Burnout and engagement among PhD students in medicine: The BEeP study. Perspect. Med. Educ. 10, 110-117. doi: $10.1007 / \mathrm{s} 40037-020-00637-6$

Larsen, J. T., and McGraw, A. P. (2011). Further evidence for mixed emotions. J. Pers. Soc. Psychol. 100, 1095-1110. doi: 10.1037/a0021846

Levecque, K., Anseel, F., De Beuckelaer, A., Van der Heyden, J., and Gisle, L. (2017). Work organization and mental health problems in $\mathrm{PhD}$ students. Res. Policy. 46, 868-879. doi: 10.1016/j.respol.2017.02.008

Liu, C., Wang, L., Qi, R., Wang, W., Jia, S., Shang, D., et al. (2019). Prevalence and associated factors of depression and anxiety among doctoral students: The mediating effect of mentoring relationships on the association between research self-efficacy and depression/anxiety. Psychol. Res. Behav. Manag. 12, 195-208. doi: 10.2147/PRBM.S195131

Magnavita, N., Chirico, F., Garbarino, S., Bragazzi, N. L., Santacroce, E., and Zaffina, S. (2021). SARS/MERS/SARS-CoV-2 outbreaks and burnout syndrome among healthcare workers. An umbrella systematic review. Int. J. Environ. Res. Public Health 18:4361. doi: 10.3390/ijerph18084361

Maslach, C. (2003). Job burnout: new directions in research and intervention. Curr. Dir. Psychol. Sci. 12, 189-192. doi: 10.1111/1467-8721.01258

Maslach, C., and Jackson, S. E. (1981). The measurement of experienced burnout. J. Organ. Behav. 2, 99-113. doi: 10.1002/job.4030020205

Maslach, C., and Leiter, M. P. (2016). Understanding the burnout experience: recent research and its implications for psychiatry. World Psychiatry 15, 103-111. doi: 10.1002/wps.20311

McAlpine, L., and Norton, J. (2006). Reframing our approach to doctoral programs: an integrative framework for action and research. High. Educ. Res. Dev. 25, 3-17. doi: 10.1080/07294360500453012

McAlpine, L., Skakni, I., and Pyhältö, K. (2020). PhD experience (and progress) is more than work: life-work relations and reducing exhaustion (and cynicism). Stud. High. Educ., 1-15. doi: 10.1080/03075079.2020.1744128

McLarnon, M. J. W., and O'Neill, T. A. (2018). Extensions of auxiliary variable approaches for the investigation of mediation, moderation, and conditional effects in mixture models. Organ. Res. Methods 21, 955-982. doi: $10.1177 / 1094428118770731$

Morin, A. J. S., Bujacz, A., and Gagné, M. (2018). Person-centered methodologies in the organizational sciences: introduction to the feature topic. Organ. Res. Methods 21, 803-813. doi: 10.1177/1094428118773856

Muthén, L. K., and Muthén, B. O. (1998-2017). Mplus User's Guide. 8th Edn. Los Angeles, CA: Muthén \& Muthén.

Nagy, G. A., Fang, C. M., Hish, A. J., Kelly, L., Nicchitta, C. V., Dzirasa, K., et al. (2019). Burnout and mental health problems in biomedical doctoral students. CBE life. Sci. Educ. 18:ar27. doi: 10.1187/cbe.18-09-0198

Naylor, R., Chakravarti, S., and Baik, C. (2016). Differing motivations and requirements in $\mathrm{PhD}$ student cohorts: A case study. Issues Educ. Res. 26, 351-367.

Nylund, K. L., Asparouhov, T., and Muthén, B. (2007). Deciding on the number of classes in latent class analysis and growth mixture modeling. A Monte Carlo simulation study. Struct. Equ. Modeling 14, 535-569. doi: 10.1080/10705510701575396

Oswalt, S. B., and Riddock, C. C. (2007). What to do about being overwhelmed: graduate students, stress and university services. Coll. Stud. Aff. J. 27, 24-44.

Pappa, S., Elomaa, M., and Perälä-Littunen, S. (2020). Sources of stress and scholarly identity: The case of international doctoral students of education in Finland. High. Educ. 80, 173-192. doi: 10.1007/s10734-019-00473-6

Peltonen, J., Vekkaila, J., Rautio, P., Haverinen, K., and Pyhältö, K. (2017). Doctoral Students' social support profiles and their relationship to burnout, drop-out intentions, and time to candidacy. Int. J. Dr. Stud. 12, 157-173. doi: $10.28945 / 3792$

Peluso, D. L., Carleton, R. N., and Asmundson, G. J. (2011). Depression symptoms in Canadian psychology graduate students: do research productivity, funding, and the academic advisory relationship play a role? Can. J. Behav Sci./Revue Canadienne des Sciences du Comportement. 43, 119-127. doi: $10.1037 / \mathrm{a} 0022624$

Pyhältö, K., Castelló, M., McAlpine, L., and Peltonen, J. (2018). The CrossCountry Doctoral Experience Survey (C-DES). User's Manual. Manual Version 2018.

Pyhältö, K., Peltonen, J., Castelló, M., and McAlpine, L. (2019). What sustains doctoral students' interest? Comparison of Finnish, UK and Spanish doctoral students' perceptions. Compare 50, 726-741. doi: 10.1080/03057925.2019.1585229

Pyhältö, K., Peltonen, J., Rautio, P., Haverinen, K., Laatikainen, M., and Vekkaila, J. (2016). Summary Report on Doctoral Experience in UNIOGS Graduate School at the University of Oulu. Acta Universitatis Ouluensis F Scripta Academica 11. University of Oulu

Pyhältö, K., Stubb, J., and Lonka, K. (2009). Developing scholarly communities as learning environments for doctoral students. Int. J. Acad. Res. 14, 221-232. doi: 10.1080/13601440903106551

Pyhältö, K., Toom, A., Stubb, J., and Lonka, K. (2012). Challenges of Becoming a Scholar: A Study of Doctoral Students' Problems and Well-Being. ISRN Education 1, 1-12. doi: 10.5402/2012/934941

Sakurai, Y., Vekkaila, J., and Pyhältö, K. (2017). More or less engaged in doctoral studies? Domestic and international students' satisfaction and motivation for doctoral studies in Finland. Res. Comp. Int. Educ. 12, 143-159. doi: $10.1177 / 1745499917711543$ 
Salmela-Aro, K., Kiuru, N., Leskinen, E., and Nurmi, J. E. (2009). School burnout inventory: reliability and validity. Eur. J. Psychol. Assess. 25, 48-57. doi: $10.1027 / 1015-5759.25 .1 .48$

Salmela-Aro, K., and Read, S. (2017). Study engagement and burnout profiles among Finnish higher education students. Burn. Res. 7, 21-28. doi: 10.1016/j. burn.2017.11.001

Salmela-Aro, K., and Upadyaya, K. (2012). The schoolwork engagement inventory: energy, dedication, and absorption (EDA). Eur. J. Psychol. Assess. 28, 60-67. doi: 10.1027/1015-5759/a000091

Salmela-Aro, K., and Upadyaya, K. (2014). School burnout and engagement in the context of demands-resources model. Br. J. Educ. Psychol. 84, 137-151. doi: 10.1111/bjep.12018

Schaufeli, W. B., Martínez, I. M., Marques Pinto, A., Salanova, M., and Bakker, A. B. (2002a). Burnout and engagement in university students. A cross-national study. J. Cross-Cult. Psychol. 33, 464-481. doi: 10.1177/0022022102033005003

Schaufeli, W. B., Salanova, M., González-Romá, V., and Bakker, A. B. (2002b). The measurement of engagement and burnout: a two sample confirmatory factor analytical approach. J. Happiness Stud. 3, 71-92. doi: 10.1023/A:1015630930326

Schmidt, M., and Hansson, E. (2018). Doctoral students' well-being: a literature review. Int. J. Qual. Stud. Health Well-being. 13:1508171. doi: 10.1080/17482631.2018.1508171

Shirom, A. (2011). Vigor as a positive affect at work: conceptualizing vigor, its relations with related constructs, and its antecedents and consequences. Rev. Gen. Psychol. 15, 50-64. doi: 10.1037/a0021853

Shraga, O., and Shirom, A. (2009). The construct validity of vigor and its antecedents: A qualitative study. Hum. Relat. 62, 271-291. doi: 10.1177/0018726708100360

Sonnentag, S. (2017). A task-level perspective on work engagement: A new approach that helps to differentiate the concepts of engagement and burnout. Burn. Res. 5, 12-20. doi: 10.1016/j.burn.2017.04.001

Stubb, J., Pyhältö, K., and Lonka, K. (2011). Balancing between inspiration and exhaustion: $\mathrm{PhD}$ students' experienced socio-psychological well-being. Stud. Contin. Educ. 33, 33-50. doi: 10.1080/0158037X.2010.515572

Sverdlik, A., Hall, N. C., McAlpine, L., and Hubbard, K. (2018). The PhD experience: a review of the factors influencing doctoral students' completion, achievement, and well-being. Int. J. Dr. Stud. 13, 361-388. doi: 10.28945/4113

Swords, B. A., and Ellis, M. V. (2017). Burnout and vigor among health service psychology doctoral students. Couns. Psychol. 45, 1141-1161. doi: 10.1177/0011000017747548

Toews, J. A., Lockyer, J. M., Dobson, D. J., Simpson, E., Brownell, A. K., Brenneis, F., et al. (1997). Analysis of stress levels among medical students, residents, and graduate students at four Canadian schools of medicine. Acad. Med. 72, 997-1002. doi: 10.1097/00001888-199711000-00019
Tuominen-Soini, H., and Salmela-Aro, K. (2014). Schoolwork engagement and burnout among Finnish high school students and young adults: profiles, progressions, and educational outcomes. Dev. Psychol. 50, 649-662. doi: $10.1037 / \mathrm{a} 0033898$

van Vendeloo, S. N., Prins, D. J., Verheyen, C. C. P. M., Prins, J. T., van den Heijkant, F., van der Heijden, F. M. M. A., et al. (2018). The learning environment and resident burnout: a national study. Perspect. Med. Educ. 7, 120-125. doi: 10.1007/s40037-018-0405-1

Vekkaila, J., Pyhältö, K., and Lonka, K. (2013). Focusing on doctoral students' experiences of engagement in thesis work. Frontline Learn. Res. 1, 12-34. doi: $10.14786 /$ flr.v1i2.43

Vekkaila, J., Pyhältö, K., and Lonka, K. (2014). Engaging and disengaging doctoral experiences in the behavioural sciences. Int. J. Behav. Dev. 5, 33-55. doi: 10.1108/IJRD-09-2013-0015

Vermunt, J. K., and Magidson, J. (2002). "Latent class cluster analysis," in Applied Latent Class Analysis. eds. J. Hagenaars and A. McCutcheon (Cambridge: Cambridge University Press), 89-106.

Virtanen, V., and Pyhältö, K. (2012). What engages doctoral students in biosciences in doctoral studies? Psychology 3, 1231-1237. doi: 10.4236/psych.2012. 312A 182

Widlund, A., Tuominen, H., and Korhonen, J. (2018). Academic well-being, mathematics performance, and educational aspirations in lower secondary education: changes within a school year. Front. Psychol. 9:297. doi: 10.3389/ fpsyg.2018.00297

Woo, T., Ho, R., Tang, A., and Tam, W. (2020). Global prevalence of burnout symptoms among nurses: A systematic review and meta-analysis. J. Psychiatr. Res. 123, 9-20. doi: 10.1016/j.jpsychires.2019.12.015

Conflict of Interest: The authors declare that the research was conducted in the absence of any commercial or financial relationships that could be construed as a potential conflict of interest.

Publisher's Note: All claims expressed in this article are solely those of the authors and do not necessarily represent those of their affiliated organizations, or those of the publisher, the editors and the reviewers. Any product that may be evaluated in this article, or claim that may be made by its manufacturer, is not guaranteed or endorsed by the publisher.

Copyright (c) 2021 Tikkanen, Pyhältö, Bujacz and Nieminen. This is an open-access article distributed under the terms of the Creative Commons Attribution License (CC BY). The use, distribution or reproduction in other forums is permitted, provided the original author(s) and the copyright owner(s) are credited and that the original publication in this journal is cited, in accordance with accepted academic practice. No use, distribution or reproduction is permitted which does not comply with these terms. 